\title{
ELETROCARDIOGRAFIA E VENTIGRAFIA NO CAVALO ATLETA
}

\section{C.L. BRANCO GERMINIANI; N. MOREIRA; A.W. BIONDO; H. GERMINIANI; A.L. ANGELI; C. SOUZA}

Departamentos de Fisiologia, de Farmacologia e de Medicina Veterinária, Curso de Pós-Graduação em Ciências Veterinárias, Setor de Ciências Biológicas, Curso de Medicina Veterinária- Campus de Palotina.

Para a avaliação da capacidade física de animais que desenvolvem atividade esportiva, cada vez mais se utilizam formas de exames não invasivos como é o caso da eletrocardiografia e da ventigrafia. Na clínica eqüina, as alterações cardíacas são menos comuns do que as respiratórias. Estas afecções chegam a ocupar a segunda posição como causa de queda do desempenho. O objetivo do presente trabalho foi determinar os parâmetros eletrocardiográficos e ventigráficos nos animais estudados. Foram utilizados ao todo 30 animais, sendo 9 Puro Sangue Inglês, 10 Quarto de Milha e 11 mestiços entre as duas raças. Estes animais eram utilizados para os esportes de corrida em cancha reta e provas de laço. Suas idades variaram de 1,5 a 12 anos, sendo 18 fêmeas e 12 machos. Os registros eletrocardiográficos foram obtidos através de um eletrocardiógrafo portátil monocanal ECG-6, com a velocidade de $25 \mathrm{~mm} / \mathrm{s}$. Para a ventigrafia foi utilizado um ventígrafo portátil cujo modelo foi padronizado pela Empresa Boehringer-Ingelheim Divisão Vetmédica. Para controle hematológico foram realizados hemogramas de todos os animais, utilizando-se sangue colhido através de punção jugular. Para realização do ECG, da ventigrafia e para a coleta de sangue os animais estavam em repouso. Para os registros eletrocardiográficos foram utilizados 24 animais. Obtiveram-se os seguintes valores médios: freqüência cardíaca $53 \pm 12,69$ batimentos por minuto, a duração de $\mathrm{P}$ foi de $0,085 \pm 0,016 \mathrm{~s}$, intervalo PR $0,2312 \pm 0,052 \mathrm{~s}$, complexo QRS $0,0812 \pm 0,0043 \mathrm{~s}$, onda T $0,0941 \pm 0,029 \mathrm{~s}$ e intervalo QT $0,40 \pm 0,0282 \mathrm{~s}$. Nas 30 ventigrafias realizadas somente 3 revelaram início de broncoespasmo nos animais investigados, com valores de pressão de 4 a $6 \mathrm{~cm}$ de água. A análise dos registros eletrocardiográficos não mostrou alterações significativas, sendo as variações encontradas meramente fisiológicas. Embora as alterações ventigráficas tenham se limitado a início de broncoespasmo, esses animais foram mantidos em observação objetivando a prevenção do desenvolvimento futuro de patologia pulmonar. Pode-se considerar que a baixa incidência de broncoespasmo esteja relacionada com a idade dos animais (maioria entre 1,5 a 2,5 anos) e com o local em que eram mantidos, pois as cocheiras eram bem arejadas e quase não havia poluição. As alterações encontradas nos hemogramas não apresentaram correlação com os resultados dos registros eletrocardiográficos e das ventigrafias.

* Os autores agradecem a colaboração da Empresa Boehringer- Ingelheim - Divisão Vetmédica. 